DIGITAL COMMONS
@ UNIVERSITY OF SOUTH FLORIDA

Volume 10

Issue 2 Fall 2020

\section{ABO: Interactive Journal for Women in the Arts, 1640-1830}

\title{
Review of Memoirs of a Woman of Pleasure by John Cleland, edited by Richard Terry and Helen Williams
}

\author{
Bethany E. Qualls \\ University of California, Davis, bequalls@ucdavis.edu
}

Follow this and additional works at: https://digitalcommons.usf.edu/abo

Part of the Educational Methods Commons, Feminist, Gender, and Sexuality Studies Commons, and the Literature in English, British Isles Commons

\section{Recommended Citation}

Qualls, Bethany E. (2020) "Review of Memoirs of a Woman of Pleasure by John Cleland, edited by Richard Terry and Helen Williams," ABO: Interactive Journal for Women in the Arts, 1640-1830: Vol.10: Iss.2, Article 7. http://doi.org/10.5038/2157-7129.10.2.1241

Available at: https://digitalcommons.usf.edu/abo/vol10/iss2/7

This Reviews is brought to you for free and open access by Digital Commons @ University of South Florida. It has been accepted for inclusion in ABO: Interactive Journal for Women in the Arts, 1640-1830 by an authorized administrator of Digital Commons @ University of South Florida. For more information, please contact digitalcommons@usf.edu. 
Review of Memoirs of a Woman of Pleasure by John Cleland, edited by Richard Terry and Helen Williams

\author{
Abstract \\ A review of Memoirs of a Woman of Pleasure by John Cleland, edited by Richard Terry and Helen \\ Williams, by Bethany E. Qualls.

\section{Keywords} \\ John Cleland, prostitute narrative, history of sexuality, teaching editions, novels, pornography, sex work, \\ eighteenth-century novel

\section{Creative Commons License} \\ (c) (i) (5)
}

This work is licensed under a Creative Commons Attribution-Noncommercial 4.0 License 
Cleland, John. Memoirs of a Woman of Pleasure. Edited by Richard Terry and Helen Williams. Broadview Press, 2018. 336 pp. ISBN: 9781554812967 / 1554812968

Reviewed by Bethany E. Qualls

University of California, Davis

Scholars and teachers of John Cleland's Memoirs of a Woman of Pleasure (174849) can rejoice: there is now a quality teaching edition of this landmark text available from Broadview. With a broader scope of materials than extant editions, Richard Terry and Helen Williams have taken full advantage of the three decades of scholarship on Cleland's novel since the Oxford (ed. Peter Sabor) and Penguin (ed. Peter Wagner) editions were both released in 1985. The result is an accessible version of the text with a more robust editorial apparatus than what has previously been available and a thorough range of supplementary primary materials.

One of the strengths here is the inclusion of eight illustrations from the 1766 edition, attributed to Hubert-François Bourguignon (known as Gravelot), a French engraver also known for his illustrations for Samuel Richardson's 1742 edition of Pamela. While Gale's Eighteenth Century Collections Online (ECCO) contains a facsimile of this particular edition and all of its 32 illustrations, the images there are only in black and white and lose much of their nuance as a result. Heretofore quality reproductions of this series could only be found in Pickering \& Chatto's Eighteenth-Century British Erotica II: Vol 4 (ed. Lena Olsson, 2004). Having this selection available for the classroom - they are spread throughout the text near the narrative section they illustrate - creates ready-built apparatus for discussions about book publishing practices, the role of illustration in interpretation, what counts as erotic, and even eighteenth-century material culture given the objects and clothing that accompany the many scenes of sexual encounter.

Other strengths include an introduction that announces previous scholarship and aims to give readers a variety of views on the text beyond its erotic content and legal troubles. The information on Cleland's life draws on Hal Gladfelder's biographical work and the editors' own project, working with Sabor, on Cleland's letters. Sections on health and disability, the history of sexuality, sex work conditions, and other novels of the period will particularly be helpful for students trying to situate the text in a classroom context, whether via a period survey or topics-based approach. Those looking to engage with work that discusses the novel's queerness, however, will need to bring in outside materials. The chronology of Cleland's life is also thorough, giving many additional details based on research since Broadview's edition of Cleland's Memoirs of a Coxcomb 
(ed. Hal Gladfelder, 2005). While there are some overlaps with the Coxcomb edition in terms of appendix materials (namely the selections from Cleland's writings on the novel and on prostitution contexts), Memoirs of a Woman of Pleasure has significantly more and richer materials to round out the trajectories laid out in the introduction. I am also especially appreciative of how this edition preserves the typography from British library/ECCO copytext, the including the multiple em dashes, italics, etc. to give the rhythm and feel of a mid-eighteenthcentury text for today's readers.

Of course, creating scholarly editions means that editors must make choices about what to include and leave out. Terry and Williams for the most part do a decent job of striking a balance between textual apparatus and leaving interpretation open for readers since too much becomes too prescriptive, but too little can lead to other kinds of frustrations of understanding. However, there are some areas where the apparatus falls short of the volume's overall excellence.

First is the description of the novel as "pornographic" on the first page of the introduction, a term that did not yet exist in the mid-1700s. In fact, "pornography" comes from the Greek for "whore's story" or "that writes about prostitutes," and was not used in English until 1842 (OED). [For the curious, Restif de la Bretonne's Le Pornographe (1769) is probably the first French use of this term.] While much scholarship has discussed the affordances of this term as a shorthand for erotic texts that seem to deliberately desire to provoke, well, sexual desire, Terry and Williams do not explicitly interrogate this term or even define it, nor mention its connection to the idea of a sex worker's story being told. As Kathleen Lubey explains in Excitable Imaginations: Eroticism and Reading in Britain, 1660-1760, using " "pornography' risks attributing to texts too singular an aim" and assigns "modern conceptions of sex to early modern culture," an argument that is usually rehearsed along with the other category designation of "erotica" by scholars of these slippery, sexy texts (30). Though Lubey's book appears in the bibliography here, the category of pornography as one that regulates - an argument found in Lynn Hunt's introduction to the 1996 The Invention of Pornography and later in scholarship by Bradford K Mudge, Ian Moulton, Sarah Toulalan, Julie Peakman, and James Grantham Turner, to name just a fewwould be worth at least a mention in the bibliography if not explicitly in the volume's introduction.

Another generic term worth some interrogation is "scandalous memoir" or "scandal memoir" $(32,35)$. The connection with Cleland's reading of Memoirs of Laetitia Pilkington is an excellent introduction to this influencer on the text, but even a brief discussion of this ambiguous genre would be helpful for non-experts 
approaching the period or text for the first time. In broad terms, calling something scandal memoir implies a morality the text is going against, but most texts thus categorized are connected by women talking about having sex. Caroline Breashears's mapping of the category and its slipperiness in "Scandalous Categories: Classifying the Memoirs of Unconventional Women" (2003) and Eighteenth-Century Women's Writing and the "Scandalous Memoir" (2016) would have been good context inclusions to reference.

Relatedly, even though most pages of the text have at least one footnote explaining terms or contexts, these notes and other editorial apparatus are uneven. For example, the selection from Thomas Stretzer's A New Description of Merryland (1741) includes a note that many of the locations mentioned are "partially obscured allusions to female genital organs," most of which are fairly obvious (such as CLTRS and UTRS) and so not footnoted (282). A note explaining MNSVNRS as mons verneris, or pubic mound is helpful for undergraduates, but the "two other Fortresses, called NMPH" has a note that says "unknown" (282-3). However, with the help of Google, I quickly found the connection to nymphae, or labia minora, a definition also found in Paul Baines and Pat Rogers's Edmund Curll, Bookseller (2007, p. 294). Perhaps the strangest omission is within the text of Memoirs itself with the double meaning of "commodity," which means goods or wares but is also a slang term for vagina. Francis Grose's definition from Classical Dictionary of the Vulgar Tongue (1785) - “a woman's commodity; the private parts of a modest woman, and the public parts of a prostitute" - makes Fanny's commentaries about a maidenhead as "a perishable commodity," or that a milliner's shop is a cover for "traffic in more precious commodities" take on yet another valence with this detail of sex's commercialization and commodification $(70,159)$. It is further perplexing that the editors can then say the novel "resolutely suppresses" money and its connection to sex work, what they term "the monetized nature of Fanny's sexual activities" (42).

For those using this text in undergraduate or graduate classrooms, more explicit connections between Cleland's novel and Samuel Richardson's Pamela would have been helpful to situate this text in the Pamela response tradition. The connections are mentioned with the oft-quoted "tail-piece of morality" as an echo of Pamela's ending, as well as the direct reference to Fielding's Shamela with "vartue" in the place of "virtue," but the editors dismiss Cleland's satire as "momentary" (34-6). However, there are well-established parallels between the two texts, from Gravelot creating plates for both texts, as well as the correspondences between Fanny and Pamela's characterization and plots. This omission is particularly puzzling given the inclusion of materials about Francis 
Charteris's rape trial and its connection to Hogarth's A Harlot's Progress, since Charteris's imprisonment and rape of Ann Bond is well-established as an influence on Richardson's plot.

Scholars beyond the undergraduate level will also find this text useful, mostly as a point of departure for deeper investigations elsewhere. The primary source clusters cover the text's censorship and later repeal, prostitution, "writing sex," and "sexual bodies," all of which have decent summaries that should give indications of which primary texts are worth trying to track down for those doing a deeper dive into such topics. Sadly, a highly useful special issue of EighteenthCentury Life (vol. 43, no. 2, April 2019), https://muse.jhu.edu/issue/40375, completely dedicated to Cleland and Memoirs of a Woman of Pleasure (honoring the novel's fiftieth anniversary of US Supreme Court exoneration) came out after this volume's publication, though Sabor's essay "Editing Memoirs of a Woman of Pleasure: New Directions" is cited here as "forthcoming." (In a twist of publications passing like ships in the night, Sabor himself notes that "After this essay was in press, an excellent teaching edition of the novel was published.") Otherwise the bibliography is nicely divided into three sections: biographies and bibliographies of Cleland, criticism on this particular novel, and contexts more broadly conceived. Considering how thorough these lists are, I was somewhat surprised to not see included highly relevant texts included such as Faramerz Dabhoiwala's The Origins of Sex: A History of the First Sexual Revolution (2012) or Pickering \& Chatto's (now part of Routledge) collection of primary texts Eighteenth-century British Erotica (10 volumes, eds. Alexander Pettit and Patrick Spedding, 2002/2004), though Whore Biographies 1700-1825 (8 volumes, ed. Julie Peakman, 2006/2007) is included. These primary text collections have excellent introductions and notes with their facsimiles which serve researchers of this text and related materials quite well.

One last thing worth mention here: seemingly all editions of Memoirs have a cover that features a naked woman on the cover, though she spends more of the book describing naked men, something that Emily West pointed out on Twitter when this edition was published. This would have been an excellent opportunity for a picture of a naked man to further set this excellent edition apart from those that came before. In the main, this edition will be useful those teaching Cleland, opening up many possible avenues for further study of a complex text. 